\title{
New Pimarane-Type Diterpenoid and ent-Eudesmane-Type Sesquiterpenoid from Bornean Liverwort Mastigophora diclados
}

\author{
Shean-Yeaw Ng, Takashi Kamada and Charles S. Vairappan *
}

Laboratory of Natural Products Chemistry, Institute for Tropical Biology and Conservation, Universiti Malaysia Sabah, 88400 Kota Kinabalu, Sabah, Malaysia

(Received April 07, 2017; Revised May 17, 2017; Accepted May 25, 2017)

\begin{abstract}
Three populations of Mastigophora diclados were collected from Mount Kinabalu, Mount Alab, and Mount Trus Madi. Each population yielded a total of four, four, and five secondary metabolites, respectively. A new compound, dicladoic acid (1) and the enantiomer of the known chlorantene $\mathrm{G}(\mathbf{8})$, along with six known compounds (2-7) were isolated from the $\mathrm{MeOH}$ extract of Bornean liverwort Mastigophora diclados. The structures of the novel metabolites were established by analyses of the spectroscopic data, including 1D NMR, 2D NMR, HRESIMS and IR. Isolated compounds shed some light into the chemosystematics of secondary metabolites in $M$. diclados. Herbertane-type sesquiterpenes were identified as the major metabolites in all three populations in Borneo and could be regarded as a suitable chemotaxonomical marker.
\end{abstract}

Keywords: Pimarane; diterpenoid; Mastigophora diclados; liverwort; Borneo Island. C 2017 ACG Publications. All rights reserved.

\section{Introduction}

The liverwort Mastigophora diclados (Bird.) Nees is a primitive plant, which has been classified into the family Lepicoleaceae, subfamily Mastigophoroideae [1]. Mastigophora is closely related to Herbertus (Herbertaceae) in its chemical composition, both having the herbertane-type sesquiterpenoids as chemical markers [2]. The liverwort M. diclados can be found in Western Europe, Southeast Africa as well as Southeast Asia regions and it is common in highlands of Malaysia. The phytochemical investigation of M. diclados from Malaysia, Japan, Taiwan, Tahiti and Madagascar has shown the presence of monomers and dimers of herbertane, macrocyclic bisbibenzyls, enttrachylobane and ent-pimarane diterpenoids [3-10]. These results showed occurrence of chemotype variations depending on geographical differences. Hence, present investigation delves upon the chemical constituents of Bornean $M$. diclados collected from three different localities. A new pimarane-type diterpenoid (1) and a new ent-eudesmane-type sesquiterpenoid (8), together with six known compounds (2-7) have been isolated. The isolation, structure elucidation and chemosystematic of the compounds are discussed.

\footnotetext{
*Corresponding author: E-Mail: csv@ums.edu.my; Phone:+60-88-320-000 Fax:+60-88-320-291
} 


\section{Materials and Methods}

\subsection{Biological Materials}

Three specimens (A1-A3) of $M$. diclados originated from natural populations of three mountain regions were collected from Mount Kinabalu (A1) $\left(6^{\circ} 1^{\prime} 52.7^{\prime}{ }^{\prime} \mathrm{N}, 116^{\circ} 32^{\prime} 59.7^{\prime}\right.$ 'E), Mount Alab (A2) $\left(5^{\circ} 40^{\prime} 11.3^{\prime \prime} \mathrm{N}, 116^{\circ} 15^{\prime} 12.044^{\prime} \mathrm{E}\right)$ and Mount Trus Madi (A3) $\left(5^{\circ} 33^{\prime} 13.1^{\prime \prime} \mathrm{N}, 116^{\circ} 30^{\prime} 41.9^{\prime \prime} \mathrm{E}\right)$ in October 2013, December 2014 and August 2015, respectively. Voucher specimens A1-A3 (BORB0002, BORB0022 and BORB0023) are deposited in the BORNEENSIS Herbarium of Institute for Tropical Biology and Conservation (BORH), Universiti Malaysia Sabah.

\subsection{Extraction and Isolation}

Air dried plant material of each specimen [A1 (80 g), A2 (40 g) and A3 (74 g)] were extracted with methanol $(\mathrm{MeOH})$ at room temperature $(1.0 \mathrm{~L}$ x 3 each for one week). The crude extract of each specimen was suspended in distilled water $(150 \mathrm{ml})$ and partitioned with ethyl acetate (EtOAc) $(50 \mathrm{ml}$ $\mathrm{x} 3$ ). The combined organic layers were dried over sodium sulfate (anhydrous) and concentrated in vacuo to afford EtOAc extracts $2.3 \mathrm{~g}(\mathbf{P 1}), 1.2 \mathrm{~g}(\mathbf{P 2})$ and $2.0 \mathrm{~g}(\mathbf{P 3})$, respectively. Each EtOAc extracts P1-P3 (1 g) were chromatographed on a Si gel column using n-hexane (Hex) and EtOAc solvent system as eluent with increasing polarity (Hex/EtOAc: 9:1, 8:2, 7:3, 6:4, 1:1, $100 \%$ EtOAc, and $\mathrm{CHCl}_{3} / \mathrm{MeOH} / \mathrm{H}_{2} \mathrm{O}: 65: 25: 4$ ) to yield seven fractions, 1-7.

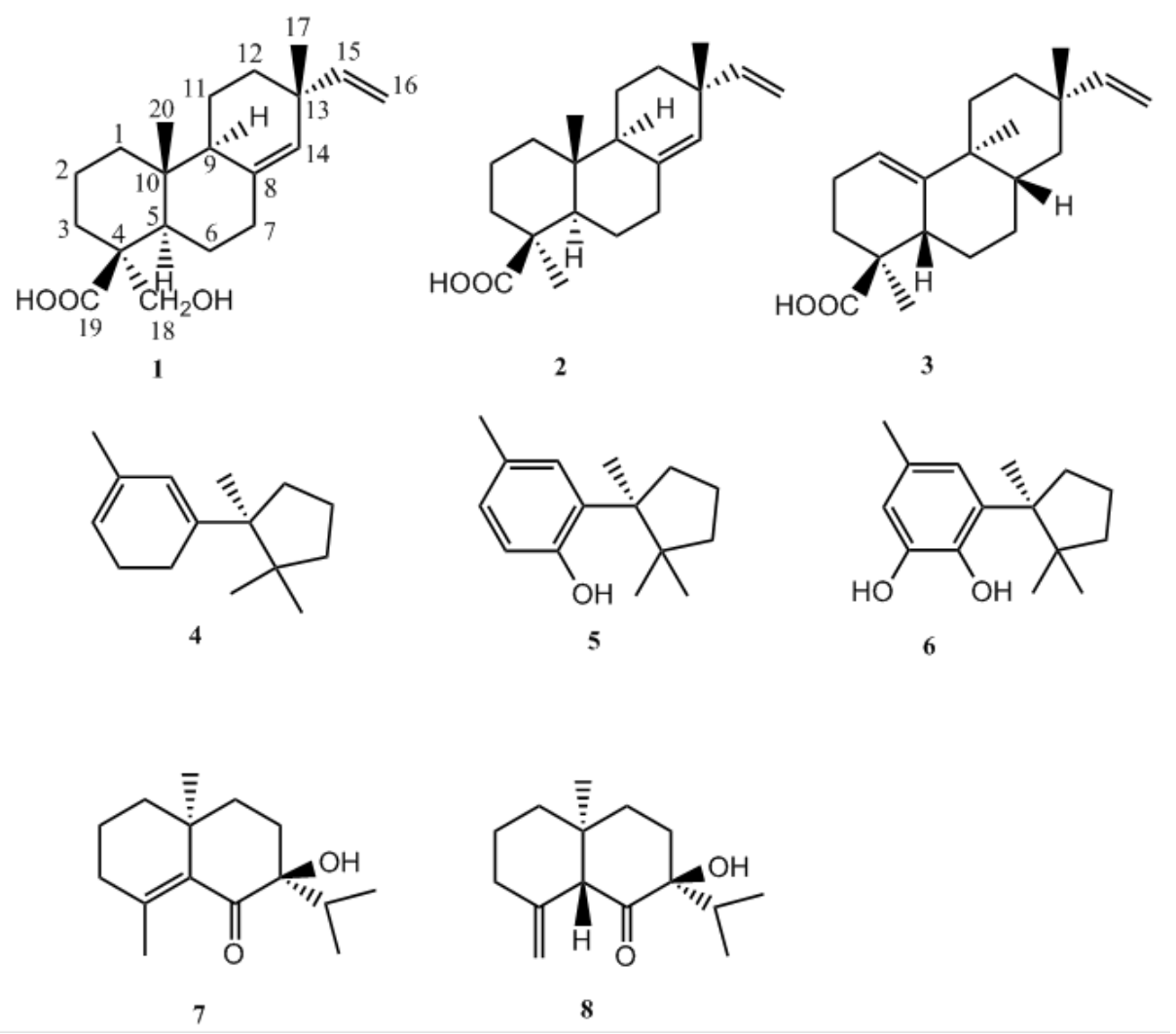

Figure 1. Structures of compounds 1-8.

P1 fraction 1 (348.0 mg) was subjected to PTLC (100\% Tol) to obtain 4 (15.6 mg) (1.6\% yield) and $5(12.4 \mathrm{mg})(1.2 \%$ yield). Fraction $2(452.7 \mathrm{mg})$ yielded $\mathbf{6}(452.7 \mathrm{mg})(45.3 \%$ yield) right 
after the open column chromatography. Compound $3(1.9 \mathrm{mg})(0.2 \%$ yield) was isolated from fraction 3 (29.8 mg) by PTLC (Hex/EtOAc: 3:1).

P2 fraction $2(210.1 \mathrm{mg})$ was subjected to PTLC (100\% Tol and Hex/EtOAc: 95:5) to yield 4 $(10.9 \mathrm{mg})$ (1.1\% yield), 7 (6.4 mg) (0.6\% yield) and $8(6.6 \mathrm{mg})(0.7 \%$ yield). Fraction $3(125.8 \mathrm{mg})$ was subjected to PTLC (Hex/EtOAc: 8:2) to give 6 ( $4.0 \mathrm{mg}$ ) (0.4\% yield).

P3 fraction $1(26.2 \mathrm{mg})$ was subjected to preparative TLC (100\% Hex) to yield 4 (2.4 $\mathrm{mg})$ ( $0.2 \%$ yield). Compounds $2(1.2 \mathrm{mg})(0.1 \%$ yield $), 5(6.4 \mathrm{mg})(0.6 \%$ yield $)$, and $\mathbf{6}(15.0 \mathrm{mg})(1.5 \%$ yield) were isolated from fraction $2(528.6 \mathrm{mg})$ by PTLC (100\% Tol and Hex/EtOAc: 9:1). Fraction 6 $(88.0 \mathrm{mg})$ was subjected to PTLC $\left(\mathrm{CHCl}_{3} / \mathrm{MeOH}: 96: 4\right)$ and afforded 1 ( $\left.4.5 \mathrm{mg}\right)(0.5 \%$ yield).

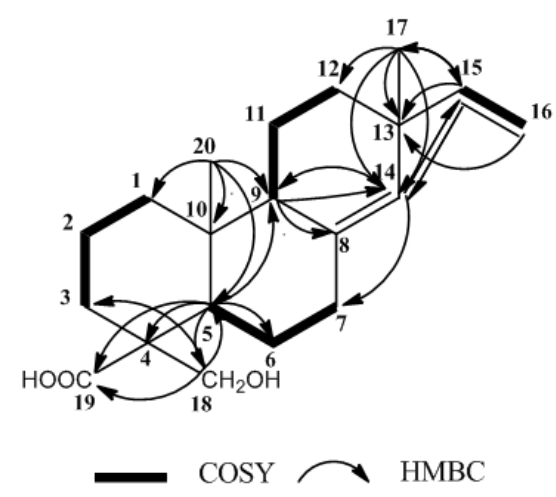

Figure 2. ${ }^{1} \mathrm{H}-{ }^{1} \mathrm{H}$ COSY correlations and the selected $\mathrm{HMBC}$ correlations of compound $\mathbf{1}$.

\section{Results and Discussion}

\subsection{Structure Elucidation}

Compound 1 was isolated as colourless oil $[\alpha]_{\mathrm{D}}^{24}+4.4\left(c 0.36, \mathrm{CHCl}_{3}\right)$. The molecular formula of 1 was determined to be $\mathrm{C}_{20} \mathrm{H}_{30} \mathrm{O}_{3}$ with six degrees of unsaturation in the molecule by HRESI-MS $\left(\mathrm{m} / \mathrm{z}, 319.2284[M+\mathrm{H}]^{+}\right.$, calcd. 319.2268) and NMR data (Table 1). The IR spectra showed the absorptions for $\mathrm{OH}$ group $\left(3390 \mathrm{~cm}^{-1}\right)$ and carbonyl group $\left(1715 \mathrm{~cm}^{-1}\right)$. The ${ }^{13} \mathrm{C}$ NMR spectrum of 1 displayed twenty signals corresponding to two methyls, nine methylenes (one being oxygenated), four methines and five quaternary carbon atoms, including a carbonyl carbon at $\delta 181.7$ (C-19). The downfield chemical shift value of the methylene group at $\delta 72.3(\mathrm{C}-18)$ indicated the attachment of the hydroxyl moiety. Structural assignments were carried out based on ${ }^{1} \mathrm{H}-{ }^{1} \mathrm{H}$ COSY and HMBC spectral data. ${ }^{1} \mathrm{H}-{ }^{1} \mathrm{H}$ COSY experiment revealed the sequences of the correlations depicted by the bold lines in Figure 2. In the HMBC experiment, the three-bond correlations of $\mathrm{H}_{3}-17$ to (C-12), (C-13), (C-14) and (C-15) confirmed the placement of the methyl group at (C-13). The other methyl group at (C-10) was confirmed by HMBC correlations between $\mathrm{H}_{3}-20$ to (C-1), (C-5), (C-9) and (C-10). Placement of the hydroxymethyl and carbonyl group at (C-4) was confirmed by the HMBC correlations of $\mathrm{H}-3$ and $\mathrm{H}-5$ to $(\mathrm{C}-18)$ as well as $\mathrm{H}-5$ to $(\mathrm{C}-4),(\mathrm{C}-6),(\mathrm{C}-18)$ and $(\mathrm{C}-19)$. The remaining connection of the double bond (C-8) was confirmed by the HMBC correlations of H-14 to (C-7) and (C-9). The presence of one carbonyl and two double-bond groups can explain three degrees of unsaturation, and the remaining three indicated the presence of a tricyclic ring. Based on these findings, the planar structure of $\mathbf{1}$ was established as shown in Figure 2.

The relative stereochemistry of $\mathbf{1}$ was deduced from the NOESY experiment. The absence of NOE correlations between $\mathrm{H}-5 / \mathrm{H}_{3}-20$ revealed the trans configuration of the decalin junction. NOE correlations observed between $\mathrm{H}-5 / \mathrm{H}_{2}-18$ showed the placement of $(\mathrm{C}-18)$. Furthermore, the expected conformational rigidity of the trans decalin system, coupled with ${ }^{1} \mathrm{H}-\mathrm{NMR}$ chemical shifts, and on same biosynthetic pathway, the $\alpha$ configuration of (C-18) as well as the $\beta$ configuration of (C-19) 
were proposed to be identical to the co-occurring compound 2 [11]. The relative stereochemistry of $\mathrm{H}$ 9 was deduced based on the cross peak observed between $\mathrm{H}-5 / \mathrm{H}-9$ in the NOESY experiment. Therefore, compound 1 was determined to be pimara-8(14),15-dien-18-ol-19-oic acid, namely dicladoic acid (Figure 1).

A total of six known compounds have been isolated, including 4-epi-sandaracopimaric acid (2) [11], rosa-1(10),15-dien-18-oic acid (3) [12], herbertene (4) [13], $\alpha$-herbertenol (5) [13], herbertene1,2-diol (6) [13], and ent-7-hydroxyeudesm-4-en-6-one (7) [14]. Furthermore, an enantiomer of eudesmane, ent-chlorantene $\mathrm{G}(\mathbf{8})$ was also isolated. The optical rotation of $\mathbf{8}\left\{[\alpha]_{\mathrm{D}}{ }^{24}-173.3(c 0.12\right.$, $\left.\left.\mathrm{CHCl}_{3}\right)\right\}$ was opposite to that of the reported chlorantene $\mathrm{G}\left\{[\alpha]_{\mathrm{D}}{ }^{20}+135.0\right\}$ [15]. The structures of these compounds were determined by comparison with reference spectral data. To the best of our knowledge as well as supported by results from SciFinder, no record of isolation of compound $\mathbf{3}$ from lower plant has been reported. Hence, this study represents the first report of the isolation of compound $\mathbf{3}$ from lower plant, Mastigophora diclados.

Table 1. ${ }^{1} \mathrm{H}$ and ${ }^{13} \mathrm{C}$ NMR data for compound $\mathbf{1}^{*}$.

\begin{tabular}{|c|c|c|}
\hline \multirow[t]{2}{*}{ Position } & \multicolumn{2}{|r|}{1} \\
\hline & ${ }^{13} \mathrm{C}$ & ${ }^{1} \mathrm{H}$ \\
\hline $1 \alpha$ & $39.5\left(\mathrm{CH}_{2}\right)$ & $1.06(1 \mathrm{H}, t d, J=4.1,13.8)$ \\
\hline $1 \beta$ & & $1.82(1 \mathrm{H}, b r d, J=13.8)$ \\
\hline $2 \alpha$ & $19.6\left(\mathrm{CH}_{2}\right)$ & $1.55-1.60(1 \mathrm{H}, m)$ \\
\hline $2 \beta$ & & $1.88(1 \mathrm{H}, d t, J=4.1,13.8)$ \\
\hline $3 \alpha$ & $33.0\left(\mathrm{CH}_{2}\right)$ & $1.12(1 \mathrm{H}, t d, J=4.1,13.1)$ \\
\hline $3 \beta$ & & $2.38(1 \mathrm{H}, b r d, J=13.1)$ \\
\hline 4 & $50.7(\mathrm{C})$ & \\
\hline 5 & $51.1(\mathrm{CH})$ & $1.38(1 \mathrm{H}, t d, J=4.1,13.8)$ \\
\hline $6 \alpha$ & $25.0\left(\mathrm{CH}_{2}\right)$ & $1.74-1.79(1 \mathrm{H}, m)$ \\
\hline $6 \beta$ & & $1.65-1.69(1 \mathrm{H}, m)$ \\
\hline $7 \alpha$ & $36.9\left(\mathrm{CH}_{2}\right)$ & $1.97(1 \mathrm{H}, t d, J=4.8,13.8)$ \\
\hline $7 \beta$ & & $2.26(1 \mathrm{H}, d q, J=2.8,4.1,13.8)$ \\
\hline 8 & $136.9(\mathrm{C})$ & \\
\hline 9 & $50.3(\mathrm{CH})$ & $1.72(1 \mathrm{H}, t, J=7.6)$ \\
\hline 10 & $39.6(\mathrm{C})$ & \\
\hline $11 \alpha$ & $19.6\left(\mathrm{CH}_{2}\right)$ & $1.48-1.54(1 \mathrm{H}, m)$ \\
\hline $11 \beta$ & & $1.55-1.60(1 \mathrm{H}, m)$ \\
\hline $12 \alpha$ & $35.1\left(\mathrm{CH}_{2}\right)$ & $1.32-1.38(1 \mathrm{H}, m)$ \\
\hline $12 \beta$ & & $1.42-1.47(1 \mathrm{H}, m)$ \\
\hline 13 & $38.0(\mathrm{C})$ & \\
\hline 14 & $129.6(\mathrm{CH})$ & $5.23(1 \mathrm{H}, b r s)$ \\
\hline 15 & $149.4(\mathrm{CH})$ & $5.76(1 \mathrm{H}, d d, J=10.3,17.2)$ \\
\hline $16 \alpha$ & $111.0\left(\mathrm{CH}_{2}\right)$ & $4.90(1 \mathrm{H}, d d, J=1.4,17.2)$ \\
\hline $16 \beta$ & & $4.88(1 \mathrm{H}, d d, J=1.4,10.3)$ \\
\hline 17 & $26.8\left(\mathrm{CH}_{3}\right)$ & $1.02(3 \mathrm{H}, s)$ \\
\hline $18 \alpha$ & $72.3\left(\mathrm{CH}_{2}\right)$ & $3.42(1 \mathrm{H}, d, J=10.3)$ \\
\hline $18 \beta$ & & $4.05(1 \mathrm{H}, d, J=10.3)$ \\
\hline 19 & $181.7(\mathrm{C})$ & \\
\hline 20 & $15.1\left(\mathrm{CH}_{3}\right)$ & $0.75(3 \mathrm{H}, s)$ \\
\hline
\end{tabular}

* $600 \mathrm{MHz}$ for ${ }^{1} \mathrm{H} \mathrm{NMR}$ and $150 \mathrm{MHz}$ for ${ }^{13} \mathrm{C} \mathrm{NMR}$ in $\mathrm{CDCl}_{3} \delta$ in ppm, $J$ in $\mathrm{Hz}$ 


\subsection{Chemosystematic of Bornean Mastigophora diclados}

Phytochemical contents of $M$. diclados collected from three different localities (Mount Kinabalu, Mount Alab and Mount Trus Madi) in Borneo Island were investigated. The occurrence of different chemotypes was detected depending on variation of localities (Table 2). Pimarane-type diterpenes (1-3) were detected in specimens from both Mount Kinabalu and Mount Trus Madi. The eudesmane-type sesquiterpenes (7-8) were detected only from Mount Alab's specimen. In addition, herbertane-type sesquiterpenes (4-6) were found as major metabolites in specimens collected from all three localities. These herbertane-type metabolites (4-6) were known to be the chemotaxonomical markers for $M$. diclados. These results suggested that the evolutionary relationship between Mount Kinabalu and Mount Trus Madi is more related compared to Mount Alab. Previous study reported the detection of Mastigophorenes [4] in specimen from Borneo Island but absent in our present study. This could be explained by the variability of $M$. diclados. Morphological study of $M$. diclados showed three different types of leave appearances which indicated the existence of three $M$. diclados varieties [16]. Microscopic investigation of specimens from Mount Kinabalu and Mount Trus Madi showed similar morphological traits whereas specimen from Mount Alab showed different leave appearance (data not shown). Our results are in consistent with previous study [16] suggesting there are three chemotypes from Bornean $M$. diclados. In conclusion, combination of both morphological traits studies and chemosystematics studies could increase the accuracy of species identification and help to resolve taxonomic problems.

Table 2. Chemotype variations of Mastigophora diclados from Borneo Island

\begin{tabular}{lccc}
\hline Specimen & \multicolumn{3}{c}{ Compounds } \\
\cline { 2 - 4 } Location & Herbertane & Pimarane & Eudesmane \\
\hline Mount Kinabalu & + & + & - \\
Mount Alab & + & - & + \\
Mount Trus Madi & + & + & - \\
\hline
\end{tabular}

+ ; -: Presence (+) and absence (-) in the specimen.

\section{Acknowledgments}

This work was supported by the Sabah Biodiversity Centre [GL0070] and Universiti Malaysia Sabah [SBK0258-SG-2016]. The authors are grateful to the Sabah Park for the support and assistance during field survey. We would also like to thank Prof. Dr. Tatsufumi Okino (Hokkaido University) for the HRMS measurements and Mr. Takafumi Ishikawa (Hokkaido University) for his assistance during data comparison.

\section{Supporting Information}

Supporting Information accompanies this paper on http://www.acgpubs.org/RNP

\section{References}

[1] Y. Asakawa, A. Ludwiczuk and F. Nagashima. (2013). Phytochemical and biological studies of bryophytes, Phytochemistry. 91, 52-80.

[2] Y. Asakawa. (2004). Chemosystematics of Hepaticae, Phytochemistry. 65, 623-669.

[3] Y.-W. Leong and L. J. Harrison. (1997). Ent-Trachylobane diterpenoids from the liverwort Mastigophora diclados, Phytochemistry. 45, 1457-1459.

[4] Y. Asakawa, X. Lin, K. Kondo and Y. Fukuyama. (1991). Terpenoids and aromatic compounds from selected East Malaysian liverworts, Phytochemistry. 30, 4019-4024. 
[5] Y. Fukuyama and Y. Asakawa. (1991). Novel Neurotrophic Isocuparane-type Sesquiterpene Dimers, Mastigophorenes A, B, C and D, Isolated from the liverwort Mastigophora diclados, J. Chem. Soc. Perkin Trans. I. 1991, 2737-2741.

[6] T. Hashimoto, H. Irita, S. Takaoka, M. Tanaka and Y. Asakawa. (2000). New Chlorinated Cyclic Bis(bibenzyls) from the Liverworts Herbertus sakuraii and Mastigophora diclados, Tetrahedron 56, 3153-3159.

[7] Y. Fukuyama, M. Toyota and Y. Asakawa. (1988). Mastigophorenes: Novel Dimeric Isocuparane-type sesquiterpenoids from the liverwort Mastigophora diclaods, J. Chem. Soc., Chem. Commun. 13411342.

[8] P. Chau and C.-L. Wu. (1987). The polar constituents of two liverwort species Mastigophora diclados and M. Woodsii, Proc. Nat. Sicen. Council, Rep. China, 11, 124-128.

[9] I. Komala, T. Ito and F. Nagashima. (2010). Cytotoxic, radical scavenging and antimicrobial activities of sesquiterpenoids from the Tahitian liverwort Mastigophora diclados (Bird.) Nees (Mastigophoraceae), J. Nat. Med. 64, 417-422.

[10] L. Harinantenaina and Y. Asakawa. (2004). Chemical Constituents of Malagasy liverworts, Part II ${ }^{1)}$ : Mastigophoric acid methyl ester of biogenetic interest from Mastigophora diclados (Lepicoleaceae Subf. Mastigophoroideae), Chem. Pharmaceut. Bull. 52, 1382-1384.

[11] L.-K. Sy and G. D. Brown. (1998). Abietane diterpenes from Illicium angustisepalum, J. Nat. Prod. 61, 907-912.

[12] F. Bohlmann, C. Zdero, J. Jakupovic, T. Gerke, M. Wallmeyer, R. M. King and H. Robinson. (1984). New sesquiterpene lactones and rosane derrivatives from Trichogonia Species, Liebigs Annalen. 1984, 162-185.

[13] A. Matsuo, S. Yuki and M. Nakayama. (1986). Structures of ent-herbertane sesquiterpenoids displaying antifungal properties from the liverwort Herberta adunca, J. Chem. Soc. Perkin Trans I. 1986, 701-710.

[14] T. Hackl, W. A. Königa and H. Muhle. (2006). Three ent-eudesmenones from the liverwort Plagiochila bifaria, Phytochemistry 67, 778-783.

[15] T. Yuan, C.-R. Zhang, S.-P. Yang, S. Y, W.-B. Wu, L. Dong and J.-M. Yue. (2008). Sesquiterpenoids and phenylpropanoids from Chloranthus serratus, J. Nat. Prod. 71, 2021-2025.

[16] S. Piippo (1984). Bryophyte flora of the Huon Peninsula, Papua New Guinea III, Annales Botan. Fenn. 21, 21-48.

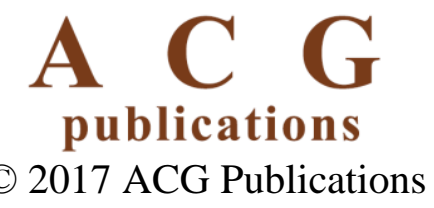

